to a fine powder in chloroform. The mixture, on stirring, at once turned dark, but no evolution of gas could be detected. The chloroform was then removed by evaporation, and a tarry mass was left. This mass was extracted repeatedly with $!$ ot ligroin. The resulting ligroin solution, on standing, deposited nodules of microscopic orange-colored needles. The yield from 5 grams of the lead salt of pyrocatechol was about 0.7 gram. The compound was purified by repeated crystallization from ligroin. Analysis gave the following:

$$
\begin{aligned}
& \text { Calculated for } \mathrm{C}_{19} \mathrm{H}_{14} \mathrm{O}_{2} \mathrm{~N}_{2}: \mathrm{C}_{1} 75.44 ; \mathrm{H}, 4.67 ; \mathrm{N}, 9.29 . \\
& \text { Found: } \quad \mathrm{C}, 75.57 ; \mathrm{H}, 5.00 ; \mathrm{N}, 9.65
\end{aligned}
$$

Benzoylorthohydroxyazobenzene melts at $93^{\circ}$. It dissolves readily in benzene, separating in nodules. It is only slightly soluble in cold alcohol. From a hot alcoholic solution, it separates in thin plates. From an acetic acid solution, it separates in clusters of lath-shaped crystals. Its saponification is best effected by adding sodium hydroxide to a hot alcoholic solution. The resulting orthohydroxyazobenzene melts at $82-83^{\circ}$. While the yield is not large, the process is so easily carried out that it serves very well as a method for preparing orthohydroxyazobenzene.

The analogues of the above compounds have been prepared and their description together with a discussion of their constitution will be given in a later paper.

onio State University, Columbus, OHIo.

\title{
THE DETERMINATION OF TOTAL SULPHUR IN URINE.
}

By otto Folin.

Received January 9, 1909.

In the January number of Thrs JournaL F. W. Gill and H. S. Grindley published a paper under the above title, the essential conclusion of which is that the sodium peroxide method described by me in $1906^{1}$ gives too low values for the total sulphur in urine and that the deficiency is due to loss of hydrogen sulphide. Gill and Grindley compare the results obtained according to my sodium peroxide method with results obtained by the nitric acid nitrate method published by Konshegg, and they assume that the higher values obtained by this later method come nearer being correct.

They further intimate that all sulphur determinations in proteins by means of alkaline fusion mixtures are probably too low because of losses of hydrogen sulphide.

A brief reply to the points raised by Gill and Grindley is, I think, called for.

${ }^{1}$ J. Biol. Chem., I, 157 (Igo6). 
(I) If Gill and Grindley worked according to my directions they could not obtain any hydrogen sulphide. There can scarcely be any doubt about this for how can hydrogen sulphide be given off from a sodium peroxide solution? That my finished fusion mixtures always contain an excess of peroxide should be clear to any one, for I give specific directions as to how this peroxide and the resulting chlorine must be removed before adding barium chloride.

(2) In my judgment the new fuming nitric acid methods are based on a very doubtful principle and so far as I know their accuracy has not been checked up. I am inclined to think that if these methods give higher figures than determinations properly made by the help of sodium peroxide it is only because in the nitric acid methods one set of errors are counteracted by another set of still greater errors. The losses of sulphuric acid by volatilization are offset by contamination with nitrates and probably also with silicates in the barium sulphate precipitates.

I may be permitted to call attention to the following determinations recorded in my paper. ${ }^{1}$

Pure cystine solution in $n /$ Io $\mathrm{HCl} ; 20 \mathrm{cc} .=76.4 \mathrm{mg}$. cystine $=148.5$ mg. $\mathrm{BaSO}_{4}$ as the theoretical value.

Found: (1) 148.9 , (2) 148.3 , (3) 148.8 , (4) 148.6 , (5) 148.2.

Average, $148.7 \mathrm{mg}$.

There is not much room for loss of hydrogen sulphide in these figures.

(3) Several years ago I used nitric acid as an auxiliary in the determination of the sulphur contents of food products. I used it according to the careful, critical directions of Hammarsten ${ }^{2}$ who twenty-five years ago determined to what extent there is danger of losing hydrogen sulphide in sulphur determinations of protein products.

HaRVard UNIVERgity, Boston, Mass.

\section{NEW BOOKS.}

The Elements of Physical Chemistry. By J. Livingston R. Morgan. Fourth Edition. New York: John Wiley \& Sons. 540 pp. Price, $\$ 3.00$.

The work is divided into the following chapters: The Gaseous State, Liquid State, Solid State, Phase Rule, Solutions, Thermochemistry, Chemical Change, Electrochemistry. It probably covers quite generally the material given in most courses of physical chemistry. It is net written in a prolix style, and the author has thus been able to introduce a very great quantity of the experimental results which illustrate the laws he considers. In most cases reference is made to the original publication, and these references are brought down to include the present

${ }^{1}$ Loc. cit., p. 158.

2Z. physiol. Chem, 9, 289 (1885). 